Research Article

\title{
Prediction of Time-Dependent Chloride Diffusion Coefficients for Slag-Blended Concrete
}

\author{
Ki-Bong Park, ${ }^{1}$ Han-Seung Lee, ${ }^{2}$ and Xiao-Yong Wang ${ }^{1}$ \\ ${ }^{1}$ College of Engineering, Department of Architectural Engineering, Kangwon National University, \\ Chuncheon-Si 200-701, Republic of Korea \\ ${ }^{2}$ Department of Architectural Engineering, Hanyang University, Ansan-Si 426-791, Republic of Korea
}

Correspondence should be addressed to Xiao-Yong Wang; wxbrave@kangwon.ac.kr

Received 25 August 2016; Accepted 10 November 2016; Published 1 January 2017

Academic Editor: Kazunori Fujikake

Copyright (C) $2017 \mathrm{Ki}$-Bong Park et al. This is an open access article distributed under the Creative Commons Attribution License, which permits unrestricted use, distribution, and reproduction in any medium, provided the original work is properly cited.

\begin{abstract}
The chloride diffusion coefficient is considered to be a key factor for evaluating the service life of ground-granulated blast-furnace slag (GGBS) blended concrete. The chloride diffusion coefficient relates to both the concrete mixing proportions and curing ages. Due to the continuous hydration of the binders, the capillary porosity of the concrete decreases and the chloride diffusion coefficient also decreases over time. To date, the dependence of chloride diffusivity on the binder hydration and curing ages of slag-blended concrete has not been considered in detail. To fill this gap, this study presents a numerical procedure to predict time-dependent chloride diffusion coefficients for slag-blended concrete. First, by using a blended cement hydration model, the degree of the binder reaction for hardening concrete can be calculated. The effects of the water to binder ratios and slag replacement ratios on the degree of the binder reaction are considered. Second, by using the degree of the binder reaction, the capillary porosity of the binder paste at different curing ages can be determined. Third, by using the capillary porosity and aggregate volume, the chloride diffusion coefficients of concrete can be calculated. The proposed numerical procedure has been verified using the experimental results of concrete with different water to binder ratios, slag replacement ratios, and curing ages.
\end{abstract}

\section{Introduction}

Chloride ingress is considered to be one of the major factors in the deterioration mechanisms of reinforced concrete in marine environments. The resulting corrosion of steel reinforcements causes serious detrimental effects, such as concrete cover cracking, reduced reinforcement in cross sections, decreased bonding between the steel rebar and concrete, and reduced yield strength and ductility of the steel rebar in reinforced concrete structures. However, to improve the resistance of concrete against chloride ingress, slag is widely used as a mineral admixture. Generally, incorporating GGBS into blended binders can increase the total porosity but will refine the pore size. Slag-blended concrete presents a lower chloride diffusivity and higher chloride binding capacity than control concrete [1].

The chloride diffusion coefficient is a key factor in the service life evaluation of slag-blended concrete. As for the chloride diffusivity in ordinary Portland cement (OPC) concrete or slag-blended concrete, Papadakis [2] and Demis et al. [3] evaluated the chloride diffusivity of fully hardened concrete as a function of the ultimate porosity. Alexander and Thomas [4] evaluated the chloride diffusivity of concrete after 28 days of curing as a function of the water to binder ratios. The Life-365 program [5] also uses the Alexander and Thomas equation [4] to determine concrete diffusivity. However, the Papadakis [2], Demis et al. [3], and Alexander and Thomas [4] models are not perfect. The Papadakis [2] and Demis et al. [3] models assume that cement is completely hydrated (i.e., the hydration degree is 100\%) regardless of the water to cement ratio. Wang and Lee [6] reported that concretes with lower water to cement ratios had slower rates of hydration and lower ultimate degrees of hydration. The chloride diffusivity calculated according to the Alexander and Thomas model [4] does not consider other factors, such as the binder content, binder reactivity, and curing methods.

The composition of hydration products, capillary porosity, and chloride diffusivity relate closely to the degree of 
hydration in hardening or hardened concrete. Han [7] and Fan and Wang [8] proposed hydration-based chloride ingress models. Time-dependent chloride diffusivity was calculated by using the development of the capillary porosity of concrete over time. However, the Han [7] and Fan and Wang [8] models do not consider the reaction of mineral admixtures and are only valid for Portland cement concrete. In the literature, some models have been proposed that evaluate the chloride diffusivity of concrete containing mineral admixtures. Song et al. $[9,10]$ calculated the final degrees of reaction of cement and silica fume in silica fume-blended concrete. The capillary porosity, chloride diffusivity, and water permeability were determined by considering the final degrees of the binder reaction and the concrete mixing proportions. Oh and Jang [11] evaluated the chloride diffusivity of fly ash and slagblended concrete by considering the final degrees of the binder reaction and the concrete porosity. However, Song et al. $[9,10]$ and Oh and Jang [11] studies are only valid for fully hardened concrete; they do not consider the dependence of chloride diffusivity on curing ages because their models do not account for the kinetic reaction processes of mineral admixtures.

As for the time dependence of chloride diffusivity, Nokken et al. [12] and Yu and Ye [13] found that chloride diffusion into concrete decreased over time. Concrete containing mineral admixtures has shown reduced chloride diffusivity compared to reference concrete. An empirical time parameter [14-16] has frequently been used to describe the age dependence of the chloride diffusion coefficient. However, this empirical time parameter cannot fully describe the evolution of the hardening concrete microstructure. The influence of various factors, such as the cement type, water to binder ratio, and slag replacement ratio, on this empirical time parameter requires further investigation [17].

To address the shortcomings of these current models, this paper presents a numerical procedure that analyzes the time dependence of the chloride diffusion coefficient. By using a blended cement hydration model, the degree of the reaction of binders and the capillary porosity of binder paste were calculated. Furthermore, the chloride diffusion coefficients at different curing ages were determined, considering the capillary porosity and aggregate volume.

\section{Cement Hydration Model and Chloride Diffusion Coefficient Model}

2.1. Cement Hydration Model. Wang and Lee $[6,18]$ proposed a hydration model for concrete containing supplementary cementitious materials, such as silica fume, fly ash, and slag. Hydration equations were proposed for cement and mineral admixtures, respectively, and the mutual interactions between cement hydration and mineral admixture reactions are considered with the capillary water content and calcium hydroxide content. The hydration model is valid for concrete with different water to binder ratios, mineral admixture replacement ratios, and curing temperatures $[6,18]$.

The reaction degrees of cement and mineral admixtures are used as fundamental indicators to evaluate the development of concrete properties. The degree of cement hydration $(\alpha)$ is defined as the ratio of the mass of hydrated cement to the mass of cement in the mixing proportion. The value of the degree of cement hydration $(\alpha)$ ranges between 0 and 1 . A degree of cement hydration of $\alpha=0$ means the absence of any hydration, and a degree of cement hydration of $\alpha=1$ means that cement has fully hydrated.

By using an integration method, the degree of cement hydration can be determined as follows:

$$
\alpha=\int_{0}^{t}\left(\frac{d \alpha}{d t}\right) d t,
$$

where $t$ is time and $d \alpha / d t$ is rate of cement hydration. The detailed equations for $d \alpha / d t$ are available in our former research $[6,18]$.

Similarly, the reaction degree of a mineral admixture $\left(\alpha_{M}\right)$ is defined as the ratio of the mass of reacted mineral admixture to the mass of the mineral admixture in the mixing proportion. The value of the degree of the mineral admixture reaction $\left(\alpha_{M}\right)$ ranges between 0 and 1. $\alpha_{M}=0$ means the absence of any mineral admixture reaction, and $\alpha_{M}=1$ indicates that the mineral admixture has reacted completely. The reaction degree of the mineral admixture reaction can also be determined using an integration method in the time domain as follows:

$$
\alpha_{M}=\int_{0}^{t}\left(\frac{d \alpha_{M}}{d t}\right) d t
$$

where $d \alpha_{M} / d t$ is the rate of the mineral admixture reaction. The detailed equations for $d \alpha_{M} / d t$ are available in our former research $[6,18]$.

In cement-mineral admixture blends, the production of chemically bound water relates to both cement hydration and mineral admixture reactions. The chemically bound water content can be determined as follows:

$$
W_{\mathrm{cbm}}(t)=0.25 * C_{0} * \alpha+0.3 * M_{0} * \alpha_{M},
$$

where $W_{\mathrm{cbm}}$ is the chemically bound water content, $C_{0}$ is the mass of cement in the mixing proportion, and $M_{0}$ is the mass of the mineral admixture in the mixing proportions. The expression $0.25 * C_{0} * \alpha$ is the mass of the chemically bound water from cement hydration, and the expression $0.3 * M_{0} *$ $\alpha_{M}$ is the mass of the chemically bound water from the slag reactions $[6,18]$.

In the cement-mineral admixture blends, both cement hydration and mineral admixture reactions contribute to the formation of gel water. The content of gel water can be calculated as follows:

$$
W_{\text {gel }}(t)=0.15 * C_{0} * \alpha+0.15 * \alpha_{M} * M_{0},
$$

where $W_{\text {gel }}$ is the mass of gel water, $0.15 * C_{0} * \alpha$ is the mass of gel water produced from cement hydration, and $0.15 * \alpha_{M} *$ $M_{0}$ is the mass of gel water produced from slag reaction.

The mass of combined water equals the sum of chemically bound water and gel water. The mass of combined water can be determined as follows:

$$
W_{c}(t)=W_{\text {gel }}(t)+W_{\mathrm{cbm}}(t),
$$

where $W_{c}(t)$ is the mass of combined water. 
In cement-mineral admixture blends, capillary water is consumed by both cement hydration and mineral admixture reactions. The capillary water content can be calculated as follows:

$$
W_{\text {cap }}(t)=W_{0}-0.4 * C_{0} * \alpha-0.45 * \alpha_{M} * M_{0},
$$

where $W_{\text {cap }}$ is the mass of capillary water in the hardening concrete and $W_{0}$ is the mass of water in the mixing proportion. The expression $0.4 * C_{0} * \alpha$ is the mass of capillary water consumed by cement hydration and the expression $0.45 * \alpha_{M} *$ $M_{0}$ is the mass of the consumed capillary water from the slag reactions.

For hardened concrete, the capillary porosity equals the sum of capillary water and chemical shrinkage. The capillary porosity can be determined as follows:

$$
\begin{aligned}
\phi_{\text {cap }}(t)= & W_{\text {cap }}(t)+0.0625 * C_{0} * \alpha+0.1 * \alpha_{M} \\
& * M_{0},
\end{aligned}
$$

where $\phi_{\text {cap }}(t)$ is the capillary porosity of hardening concrete, $0.0625 * C_{0} * \alpha$ is the chemical shrinkage from cement hydration, and $0.1 * \alpha_{M} * M_{0}$ is the chemical shrinkage from slag reactions.

2.2. Chloride Diffusion Coefficient Model. Concrete is a threephase material consisting of a cement paste matrix, aggregate, and interfacial transition zones (ITZs) between the cement paste matrix and aggregate. The interfacial transition zone has a higher capillary porosity and contains higher calcium hydroxide volume fractions compared to the bulk matrix. Interfacial zones are formed due to the particle-packing effect and the one-sided growth effect [19]. The particlepacking effect arises because the cement particles cannot pack together as well near a flat edge as in a free space. The onesided growth effect is reactive growth from the cement side, but not from the aggregate side. The cement paste matrix is interconnected through interfacial transition zones. Garboczi [19] found that when the aggregate volume fractions are greater than $50 \%$, the interfacial transition zone will be fully percolated. This observation agrees with the experimental results from Princigallo et al. [20]. Because most concretes have aggregate volume fractions above $50 \%$, the interfacial transition zones in the usual concrete are percolated.

Due to the cement particle-packing effect, the ITZ shows a higher water to cement ratio. Therefore, the effective water to cement ratio in the bulk cement paste will be reduced. Nadeau [20, 21] proposed a model to consider water to cement gradients between the aggregate and bulk cement paste. The model is a function of the overall water-cement ratio, volume fraction and radius of the aggregate, specific gravity of cement, and thickness of the ITZ. The equations for determining the effective water to binder ratio of bulk cement paste in concrete are given as follows $[21,22]$ :

$$
\begin{aligned}
& \overline{V_{C}} \\
& =\frac{10\left(1-V_{a}\right)}{\left(1+\left(W_{0} /\left(C_{0}+M_{0}\right)\right) G_{C}\right)\left[a_{c} V_{a} \varepsilon\left\{\varepsilon^{2}+5 \varepsilon+10\right\}+10\left(1-V_{a}\right)\right]}, \\
& \overline{W_{C}}=\frac{1-\overline{V_{C}}}{G_{C} \overline{V_{C}}},
\end{aligned}
$$

where $\overline{V_{C}}$ is the binder volume fraction in the bulk binder paste, $V_{a}$ is the volume of the aggregate, $W_{0} /\left(C_{0}+M_{0}\right)$ is the overall water to binder ratio of concrete, $G_{C}$ is the specific gravity of the binder, $a_{c}$ is a constant equal to approximately -0.5 , and $\varepsilon$ is the thickness ratio of ITZ. $\overline{W_{C}}$ is the effective water to binder ratio in the bulk binder paste, whereas $1-\overline{V_{C}}$ indicates the water volume fraction in the bulk binder paste.

The diffusivity of the cement paste phase $D_{P}$ is mainly dependent on the capillary pores in the cement paste, which can be determined as follows [8]:

$$
\begin{aligned}
D_{P}(t) & =A_{1} *\left(\phi_{\text {paste }}\right)^{A_{2}}, \\
\phi_{\text {paste }} & =\frac{\phi_{\text {cap }}}{V_{P}},
\end{aligned}
$$

where $A_{1}$ and $A_{2}$ are the relation coefficients between the capillary porosity and chloride diffusivity, respectively; $\phi_{\text {paste }}$ is the capillary porosity in the binder paste; and $V_{P}$ is volume of binder paste calculated from the effective water to binder ratio $\overline{W_{C}}$. In (9), the intrinsic diffusion coefficient $A_{1}$ relates to the type of binder, such as cement or slag. Exponent $A_{2}\left(A_{2}>\right.$ 1) relates to the pore size distribution or the complexity of the microstructure of the reaction products. As shown in (9) and (10), with the progress of binder hydration, the capillary porosity of concrete decreases and the chloride diffusion coefficient decreases correspondingly.

When the diffusivity of the aggregate particle inclusions is assumed to be zero, according to the composite sphere assemblage (CSA) model [11], the chloride diffusion coefficient of concrete can be determined as follows:

$$
\frac{D}{D_{P}}=1+\frac{V_{a}}{1 /\left(2\left(D_{i} / D_{P}\right) \varepsilon-1\right)+\left(1-V_{a}\right) / 3},
$$

where $D$ is the diffusivity of concrete and $D_{i}$ is the diffusivity in the interfacial transition zone.

By using a hard core/soft shell model, Garboczi [19] evaluated the connectivity of the interfacial zones for different choices of interfacial zone thicknesses. Furthermore, by comparison with cement mortar mercury intrusion data [23], a choice of $20 \mu \mathrm{m}$ for the interfacial zone thickness was found to give the best agreement with the mercury data. The mean radius of coarse aggregate is approximately $10 \mathrm{~mm}$. Hence, in this study, a thickness ratio of ITZ of approximately $\varepsilon=0.002$ is used.

Bentz and Garboczi [24] studied the effects of mineral admixtures on the interfacial transition zone. They found that smaller admixtures allow better packing nearer to the aggregate edge, and the reactivity of the mineral admixture controls the consumption of the calcium hydroxide. For fly ash blended mortar, the fraction ratio of CSH between ITZ and the bulk matrix is similar to plain cement mortar [22]. Similarly, based on an analysis of the chloride diffusivity of concrete with various fly ash and slag additions, Oh and Jang [11] proposed that, for Portland cement concrete, fly ash blended concrete, and slag-blended concrete, the ratios between $D_{i}$ and $D_{P}$ are almost the same $\left(D_{i} / D_{P}=7\right)$.

The effects of slag addition on the chloride diffusion coefficients of concrete are summarized as follows: first, 
TABLE 1: Properties of binders [15].

\begin{tabular}{lccccccccc}
\hline \multirow{2}{*}{ Types } & \multicolumn{9}{c}{ Chemical composition (mass\%) } \\
& $\mathrm{SiO}_{2}$ & $\mathrm{Al}_{2} \mathrm{O}_{3}$ & $\mathrm{Fe}_{2} \mathrm{O}_{3}$ & $\mathrm{CaO}$ & $\mathrm{MgO}$ & $\mathrm{SO}_{3}$ & Lg. loss & Specific gravity $\left(\mathrm{g} / \mathrm{cm}^{3}\right)$ & $\mathrm{Blaine}\left(\mathrm{cm}^{2} / \mathrm{g}\right)$ \\
\hline Cement & 21.96 & 5.27 & 3.44 & 63.41 & 2.13 & 1.96 & 0.79 & 3.16 & 3214 \\
Slag & 32.74 & 13.23 & 0.41 & 44.14 & 5.62 & 1.84 & 0.2 & 2.89 & 4340 \\
\hline
\end{tabular}

TABLE 2: Mixing proportions of concrete [15].

\begin{tabular}{|c|c|c|c|c|c|c|c|}
\hline$W / B^{1}$ & $S / B^{2}$ & Water & Cement $\left(\mathrm{kg} / \mathrm{m}^{3}\right)$ & Slag $\left(\mathrm{kg} / \mathrm{m}^{3}\right)$ & Sand $\left(\mathrm{kg} / \mathrm{m}^{3}\right)$ & Gravel $\left(\mathrm{kg} / \mathrm{m}^{3}\right)$ & Superplasticizer (\% of binder) \\
\hline 0.37 & 0 & 168 & 454 & 0 & 767 & 952 & $1 \%$ \\
\hline 0.42 & 0 & 168 & 400 & 0 & 787 & 976 & $0.9 \%$ \\
\hline 0.47 & 0 & 168 & 357 & 0 & 838 & 960 & $0.85 \%$ \\
\hline 0.37 & 0.3 & 168 & 318 & 136 & 762 & 946 & $0.8 \%$ \\
\hline 0.42 & 0.3 & 168 & 280 & 120 & 783 & 972 & $0.75 \%$ \\
\hline 0.47 & 0.3 & 168 & 250 & 107 & 835 & 956 & $0.65 \%$ \\
\hline 0.37 & 0.5 & 168 & 227 & 227 & 760 & 943 & $0.75 \%$ \\
\hline 0.42 & 0.5 & 168 & 200 & 200 & 780 & 969 & $0.7 \%$ \\
\hline 0.47 & 0.5 & 168 & 178 & 179 & 832 & 853 & $0.6 \%$ \\
\hline
\end{tabular}

${ }^{1}$ Water to binder ratio. ${ }^{2}$ Slag to binder ratio.

incorporating GGBS into blended binders can increase the total porosity because the reactivity of slag is lower than the reactivity of cement. This point is considered using slagblended cement hydration models ((1) and (7)). Second, calcium silicate hydrate $(\mathrm{CSH})$ gel produced from slag reactions has finer gel pores than the gel from cement hydration. This effect is considered using an intrinsic diffusion coefficient $A_{1}$ in (9). Third, the formation of slag reaction products can fill large capillary voids and reduce the average pore size. This effect is considered using a chloride diffusion exponent $A_{2}$ in (9). In our study, the evolution of the chloride diffusion coefficient over time is directly related to the timedependent development of capillary porosity. We do not use the empirical time parameter [14-16] to describe the age dependence of the chloride diffusion coefficient. Compared with the empirical time parameter method [14-16], the physical meaning of the model proposed in this study is much clearer.

However, the proposed model in this study for the chloride diffusion coefficient of concrete shows some limits. First, the chloride diffusivity in the ITZ is dependent on the distance from the aggregate surface $[25,26]$. The chloride diffusivity in the ITZ is not analyzed in detail in this study. Second, for hardening concrete, the moisture transport from the water-rich ITZ to the drying bulk paste is not considered [25]. Water transport plays a prominent role in the hardened ITZ microstructure [27]. Therefore, the present version of the proposed model is not perfect and needs to be improved.

\section{Verification of the Proposed Model}

The experimental results from Song and Kwon [15] were used to verify the proposed model. Song and Kwon [15] performed a systematic experimental study of the chloride diffusivity of slag-blended concrete. They measured a chloride diffusion coefficient for slag-blended concrete with various mixing proportions at different curing ages. Table 1 shows the chemical and physical properties of the cement and slag. Table 2 shows the mixing proportions of the concrete specimens. Concrete specimens with three different water to binder ratios of $0.47,0.42$, and 0.37 and two different slag contents of $30 \%$ and $50 \%$ were prepared. Concrete cylinder specimens were cured under moist conditions. At curing periods of 28 days (four weeks), 90 days (three months), 180 days (six months), and 270 days (nine months), the chloride diffusion coefficients were measured through an electrical accelerated method. After the electrical accelerated test, a silver nitrate solution $\left(\mathrm{AgNO}_{3}\right.$ with a concentration of $\left.0.1 \mathrm{~mol} / \mathrm{L}\right)$ was used as an indicator to measure the chloride penetration depth that was achieved, and the chloride diffusion coefficient was calculated according to the penetration depth [15]. The diffusion coefficient determined by this test is a migration coefficient, which does not include binding, among other effects.

3.1. Reaction Degree of Cement. The addition of slag presents a dilution effect on cement hydration. A dilution effect means that, in cement-slag blends, the addition of slag makes the water to cement ratio increase. As shown in Figures 1(a) and 1(b), in cement-slag blends, the reaction degree of cement is higher than in plain cement paste. The more the slag additions, the higher the reaction degree of cement. When the water to binder ratio increases from 0.37 (Figure $1(\mathrm{a})$ ) to 0.47 (Figure $1(\mathrm{~b})$ ), the degree of cement hydration increases because the concentration of the capillary water and available deposit space of hydration products increases.

3.2. Reaction Degree of Slag. The slag reaction relates to both the water to binder ratios and slag replacement ratios. As shown in Figures 2(a) and 2(b), when the water to binder ratio increases from 0.37 to 0.47 , the reaction degree of the slag increases because the concentration of capillary water and 


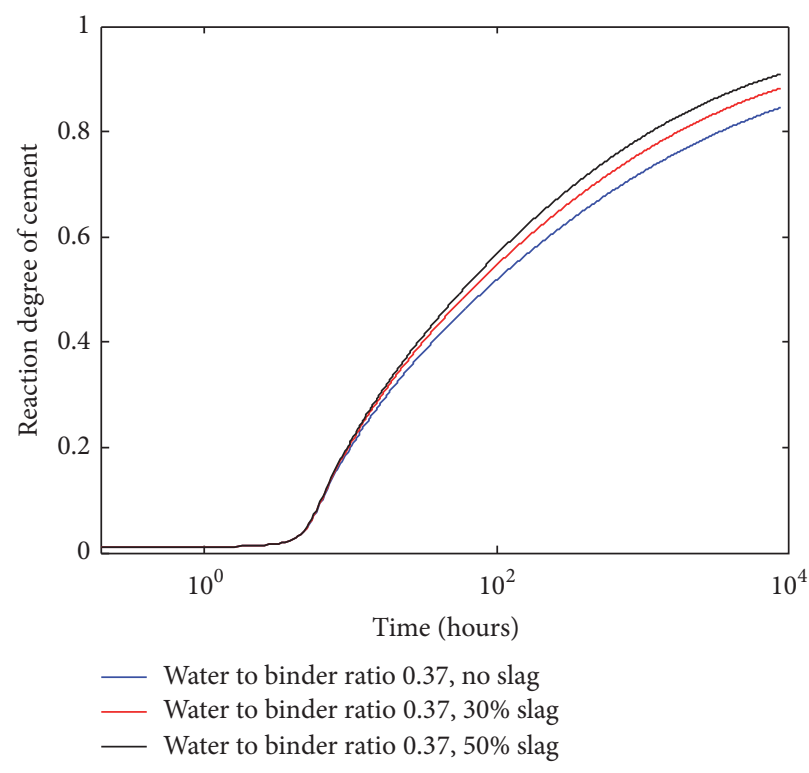

(a) Water to binder ratio 0.37

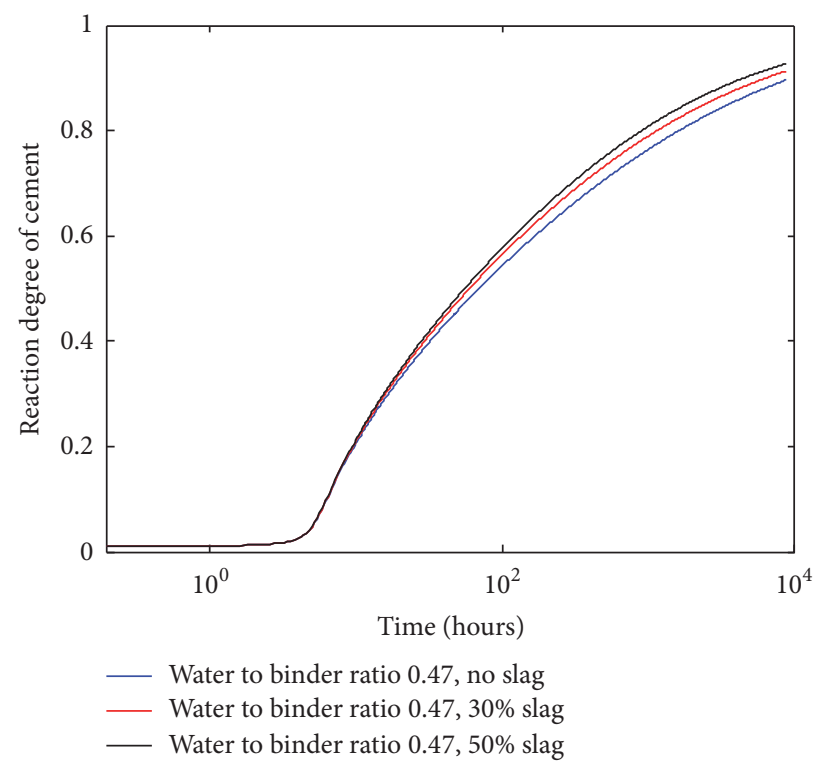

(b) Water to binder ratio 0.47

Figure 1: Reaction degree of cement.

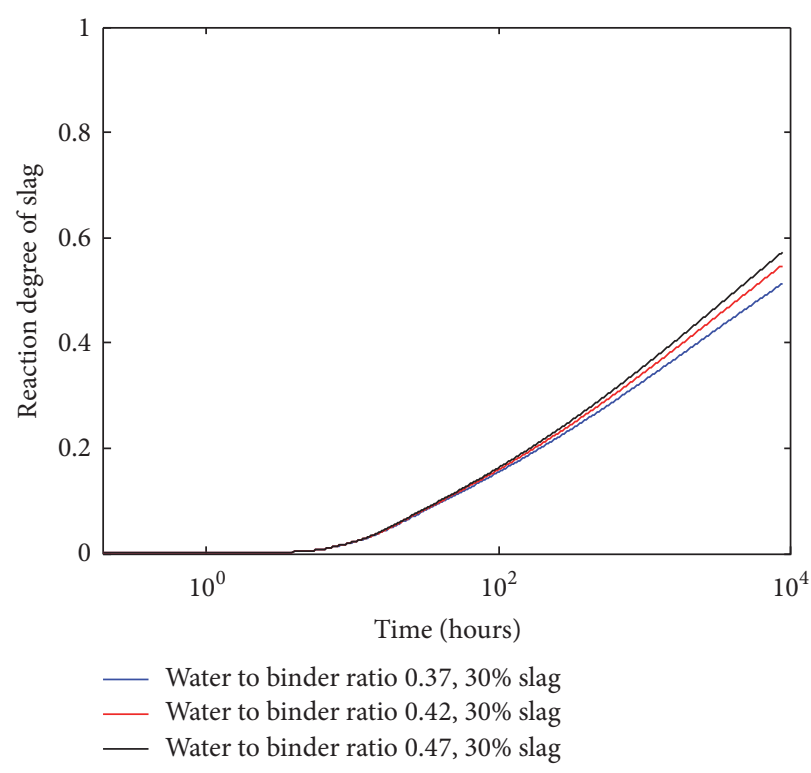

(a) Slag replacement ratio $30 \%$

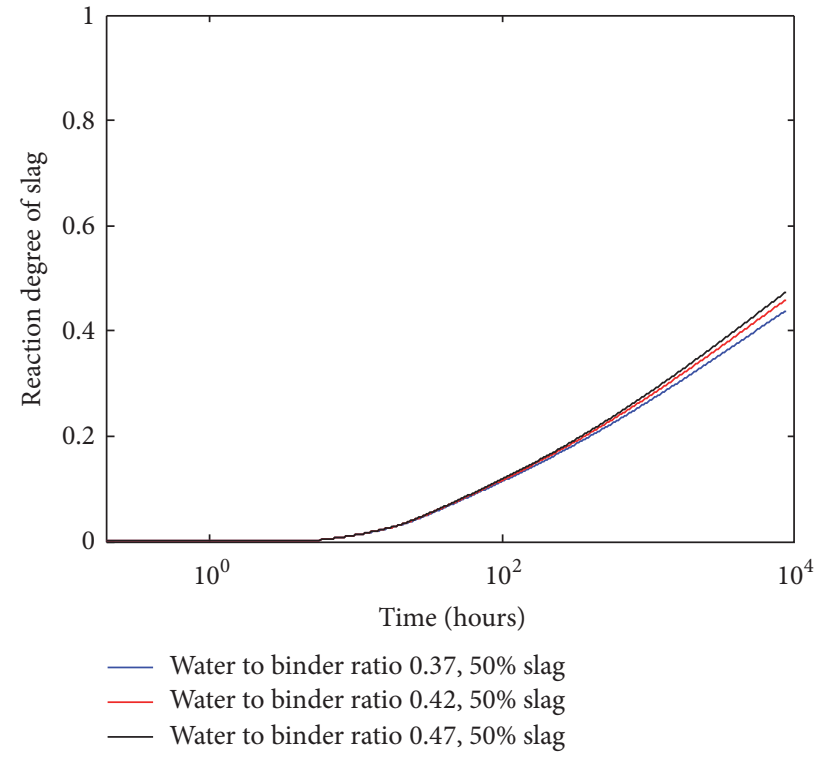

(b) Slag replacement ratio $50 \%$

FIGURE 2: Reaction degree of slag.

available deposit space of the hydration products increases. However, when the slag replacement ratio increases from $30 \%$ (Figure 2(a)) to 50\% (Figure 2(b)), the reaction degree of the slag decreases because the alkali activation effect on the slag reaction becomes weaker.

3.3. Combined Water. As shown in (3)-(5), both cement hydration and the slag reaction contribute to the production of combined water. Figure 3 shows the amount of combined water as a function of curing ages. As shown in Figures 3(a) and $3(b)$, when the water to binder ratio increases from 0.37 to
0.47 , the amount of combined water decreases. For concrete containing 50\% slag (Figure 3(b)), the amount of combined water is lower than in plain concrete (Figure 3(a)) because the reaction rate of slag (shown in Figure 2) is much slower than the reaction rate of cement (shown in Figure 1).

3.4. Capillary Porosity. In hydrating cement-slag blends, with the increase in combined water, the reaction products deposit in the capillary pore space and the capillary porosity decreases. Figure 4 shows the amount of capillary porosity in binder paste as a function of the curing ages. As shown in 


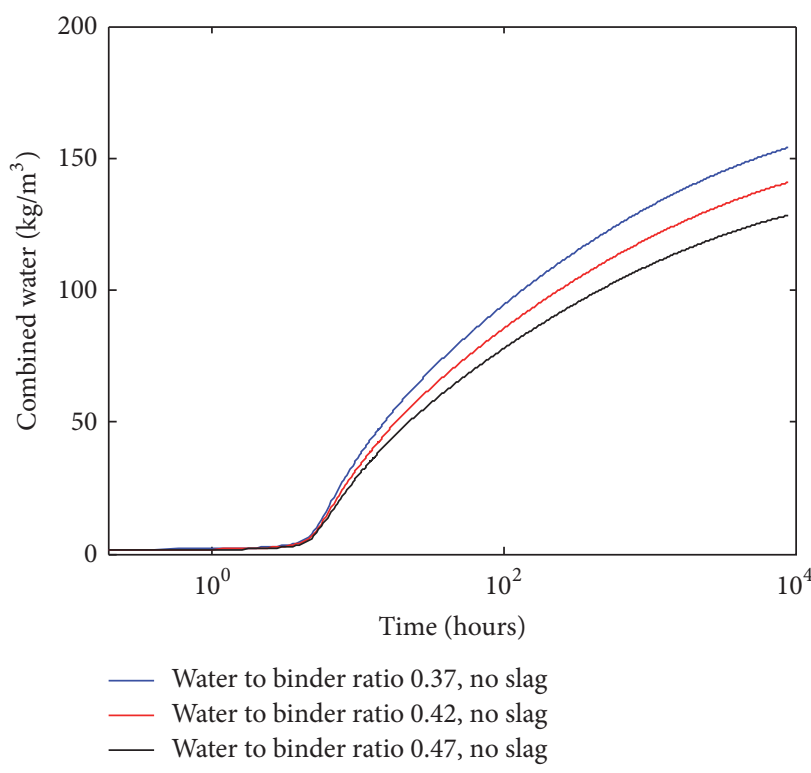

(a) Plain concrete

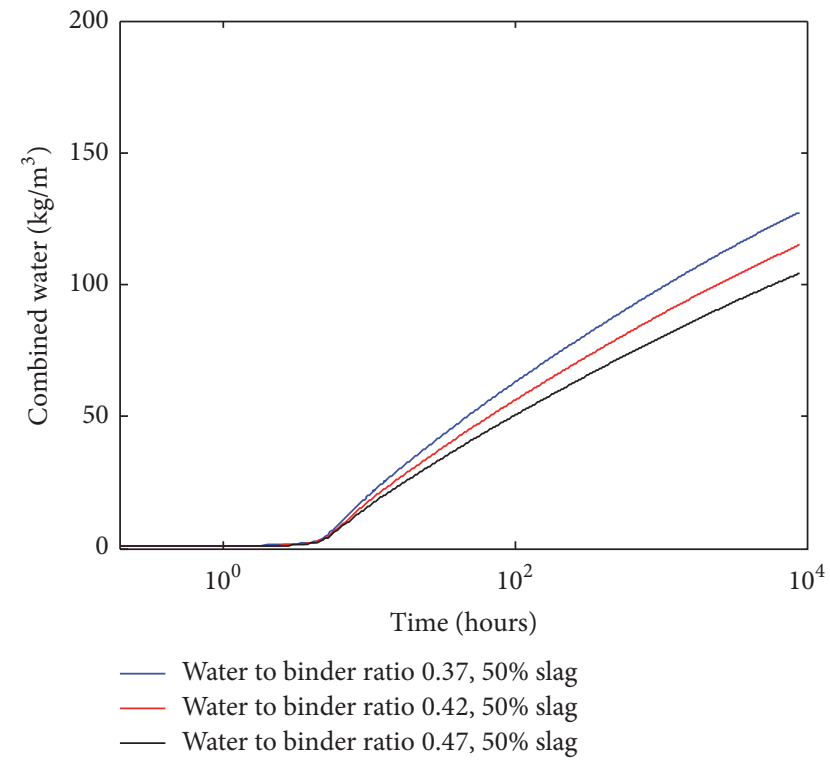

(b) $50 \%$ slag concrete

FIGURE 3: Combined water.

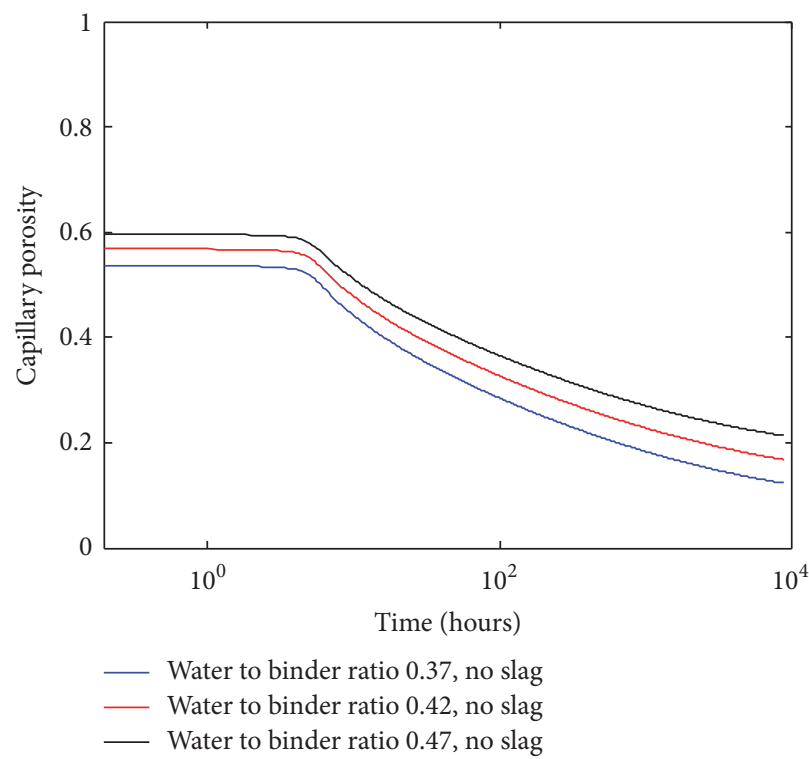

(a) Plain concrete

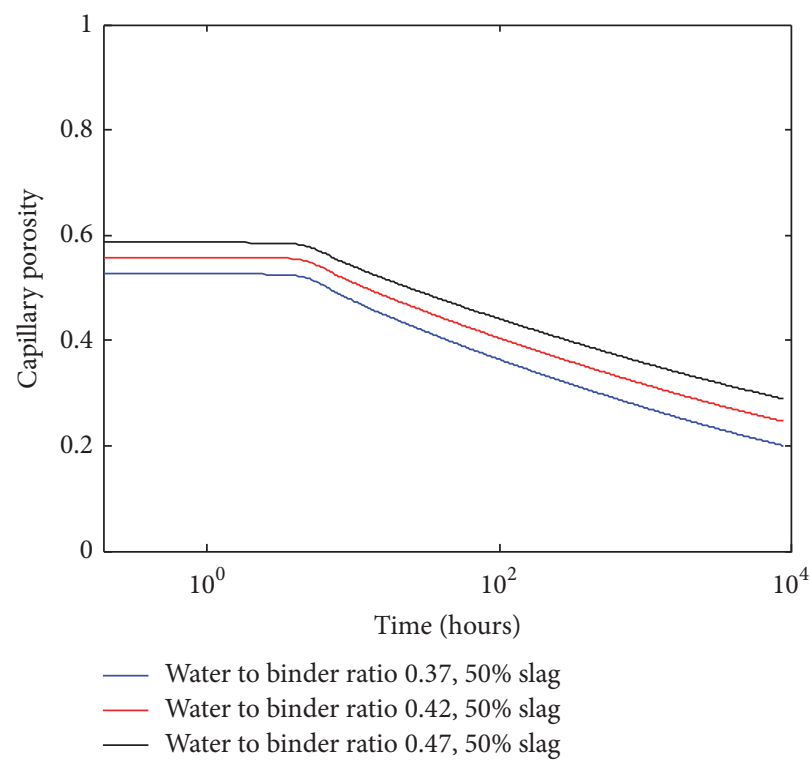

(b) $50 \%$ slag concrete

FIgURE 4: Capillary porosity.

Figure 4, when the water to binder ratio increases from 0.37 to 0.47 , the amount of capillary porosity increases. For concrete containing $50 \%$ slag, the amount of capillary porosity is higher than in plain concrete.

\subsection{General Equation of the Chloride Diffusion Coefficient} for Slag-Blended Concrete. As mentioned in Section 2.2, the intrinsic diffusion coefficient $A_{1}$ and exponent $A_{2}$ in (9) are not dependent on the water to binder ratios and only relate to the type of binders. We assume that cement and slag contribute to both the intrinsic diffusion coefficient $A_{1}$ and the exponent $A_{2}$ relating to binder weight fractions as follows:

$$
\begin{aligned}
& A_{1}=B_{1} * \frac{C_{0}}{C_{0}+M_{0}}+B_{2} * \frac{M_{0}}{C_{0}+M_{0}} \\
& A_{2}=C_{1} * \frac{C_{0}}{C_{0}+M_{0}}+C_{2} * \frac{M_{0}}{C_{0}+M_{0}},
\end{aligned}
$$




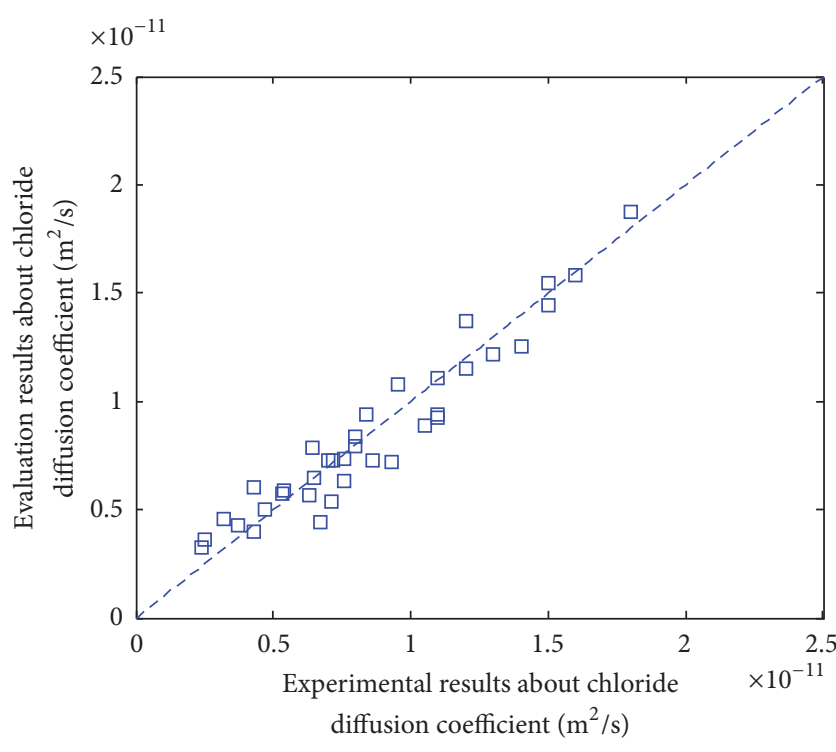

Figure 5: Comparisons between experimental results and analyzed results.

where $B_{1}$ and $B_{2}$ are the contributions of cement and slag, respectively, to the intrinsic diffusion coefficient $A_{1} ; C_{1}$ and $C_{2}$ are the contributions of cement and slag, respectively, on the exponent $A_{2} \cdot C_{0} /\left(C_{0}+M_{0}\right)$ and $M_{0} /\left(C_{0}+M_{0}\right)$ are the weight fractions of cement and slag, respectively, in cementslag blends. As shown in (12), when the replacement ratio of slag equals zero, the chloride diffusion coefficient is only dependent on the values of $B_{1}$ and $C_{1}$, which relate to cement. When slag is used as a mineral admixture, the chloride diffusion coefficient is dependent on the values of $B_{1}, B_{2}, C_{1}$, and $C_{2}$.

Using the experimental results from chloride diffusion coefficients measured at different ages for various mixing proportions, the values of $B_{1}, B_{2}, C_{1}$, and $C_{2}$ are calibrated as $3.90 e-10,0.72 e-10,1.21$, and 2.31 , respectively. As shown in Figure 5, the analyzed results generally agree with the experimental results. The correlation coefficient between the analyzed results and experimental results is 0.96 . The addition of slag can reduce the intrinsic chloride diffusion coefficient $A_{1}$ (because $B_{1}>B_{2}$ ) because the gel produced from the slag reaction has finer gel pores than the gel produced from cement hydration. In addition, the addition of slag can increase the chloride diffusion exponent $A_{2}$ (because $C_{1}<C_{2}$ ). This increase may be due to the pore size refinement effect resulting from the slag reactions. With the reduction of the intrinsic chloride diffusion coefficient $A_{1}$ and the increase of the chloride diffusion exponent $A_{2}$, the chloride diffusion coefficients decrease correspondingly.

The relationship between capillary porosity in the binder paste and the chloride diffusion coefficients is shown in Figure 6(a). As seen in Figure 6(a), given the same capillary porosity, the chloride diffusion coefficients of slag-blended concrete are much lower than the chloride diffusion coefficients of Portland cement concrete, possibly because the formation of slag reaction products can fill large capillary voids and reduce the average pore size [6]. As shown in Figures 6(b)-6(d), the analyzed results generally agree with the experimental results. With increasing slag replacement levels or decreasing water to binder ratios, the chloride diffusion coefficients decrease. By relating the chloride diffusion coefficients to binder hydration, the proposed model can generally reflect the dependence of chloride diffusion coefficients on the curing ages, water to binder ratios, and slag content. However, because the proposed model does not consider the evolution of the $\mathrm{Ca} / \mathrm{Si}$ ratio in calcium silicate hydrate (CSH) during the binder hydration process [6], the analyzed results show slight deviations from experimental results (especially for $50 \%$ slag concrete).

3.6. Comparison with Life-365 Model. In addition to our analysis results, the analyzed results from the Life-365 program [5] are shown in Figure 7. In the Life-365 program, the time-dependent chloride diffusion coefficient is calculated as follows:

$$
\begin{aligned}
D(t) & =D_{\text {ref }}\left(\frac{t_{\text {ref }}}{t}\right)^{m}, \\
D_{\text {ref }} & =10^{(-12.06+2.4 \mathrm{w} / \mathrm{cm})} \\
m & =0.2+0.4\left(\frac{\% \mathrm{FA}}{50}+\frac{\% \mathrm{SG}}{70}\right),
\end{aligned}
$$

where $D_{\text {ref }}$ is the chloride diffusion coefficient at time $t_{\text {ref }}=$ 28 days, $m$ is the diffusion decay index, w/cm is the watercementitious material ratio, and \% FA and \% SG are the levels of fly ash and slag, respectively, in the mixtures. The Life-365 program assumes that fly ash or slag does not affect the early age chloride diffusion coefficient $D_{\text {ref }}$ (chloride diffusion coefficient at 28 days). The Life-365 program considers that fly ash and slag impact the rate of reduction in diffusivity only over time. With the increase of the slag or fly ash replacement levels, the value of $m$ increases and more reduction in chloride diffusivity occurs over time. As shown in Figure 7, the trends of the calculation results from the Life365 program are similar to our proposed model. However, for Portland cement concrete (Figure $7(\mathrm{a})$ ) and 30\% slag concrete (Figure $7(\mathrm{~b})$ ), the chloride diffusivity calculated from the Life-365 program is lower than the experimental results, possibly because the reactivity of cement and aggregate content in our study are different from those in the Life-365 program.

\section{Conclusions}

This study presents a numerical procedure to predict the time-dependent chloride diffusion coefficients of slagblended concrete. This numerical procedure starts with a slag-blended cement hydration model. The reaction degree of the binders is calculated using this hydration model. By using the reaction degree of binders, the combined water 


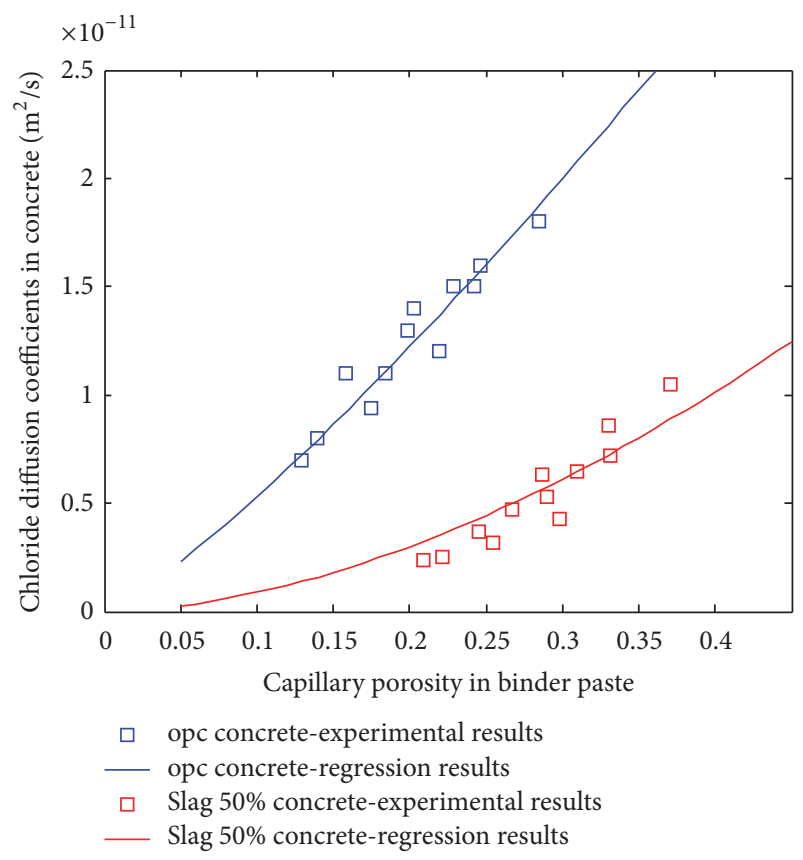

(a) Relationship between diffusion coefficients and capillary porosity

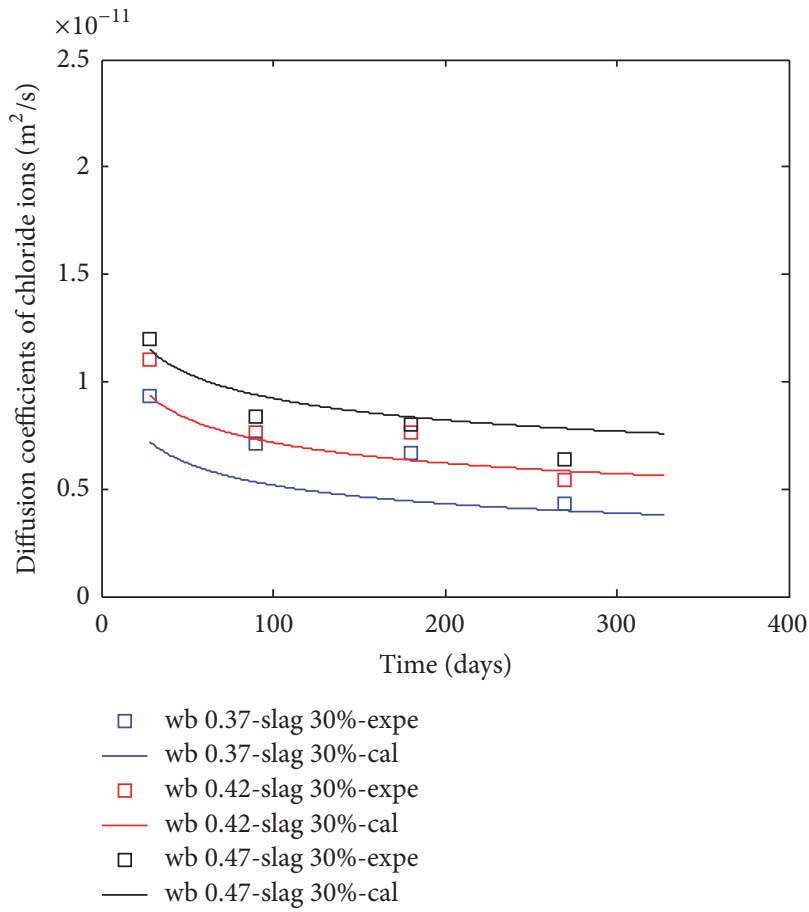

(c) $30 \%$ slag concrete

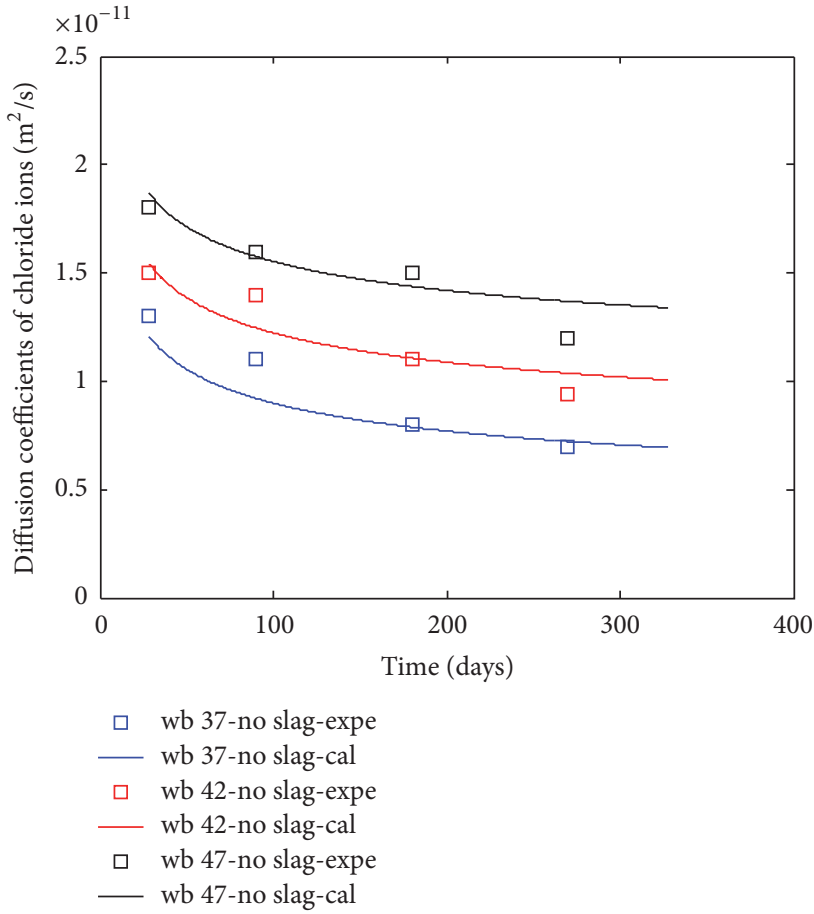

(b) Portland cement concrete

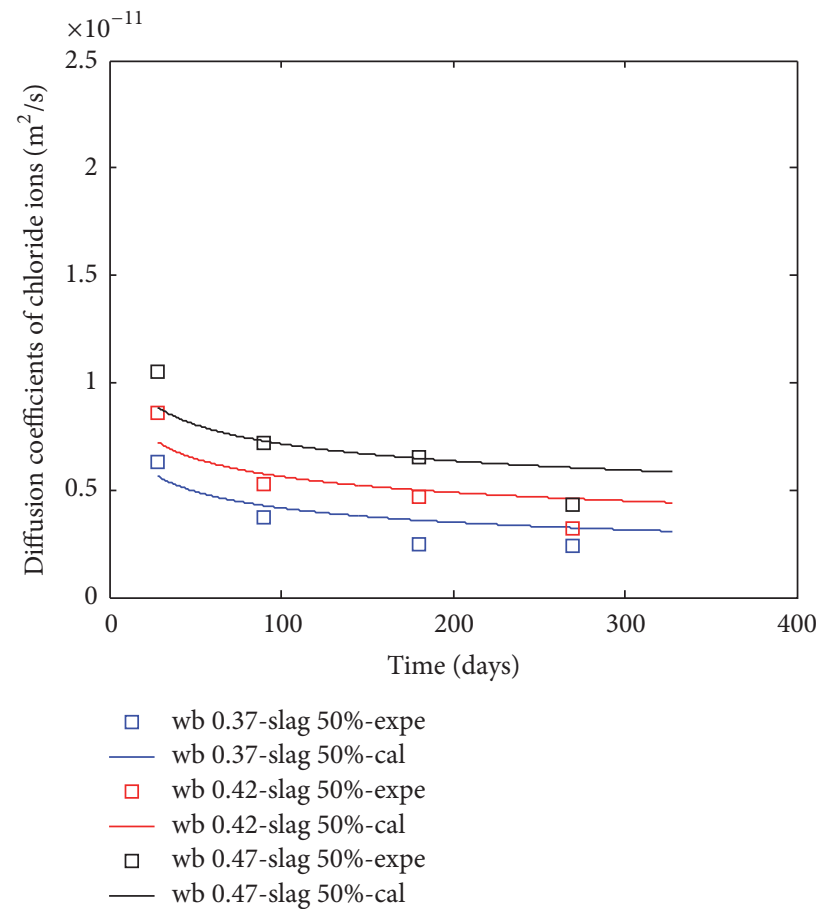

(d) $50 \%$ slag concrete

FIgURE 6: Chloride diffusion coefficients.

and capillary porosity of hardening concrete at different curing ages is determined. Furthermore, by using the capillary porosity and aggregate volume, the chloride diffusion coefficients are calculated. A general equation for the chloride diffusion coefficient for hardening slag-blended concrete is proposed. The increase of total porosity due to slag addition, pore refinement on the macroscale by slag due to the filling effect, and pore refinement on the microscale due to the 


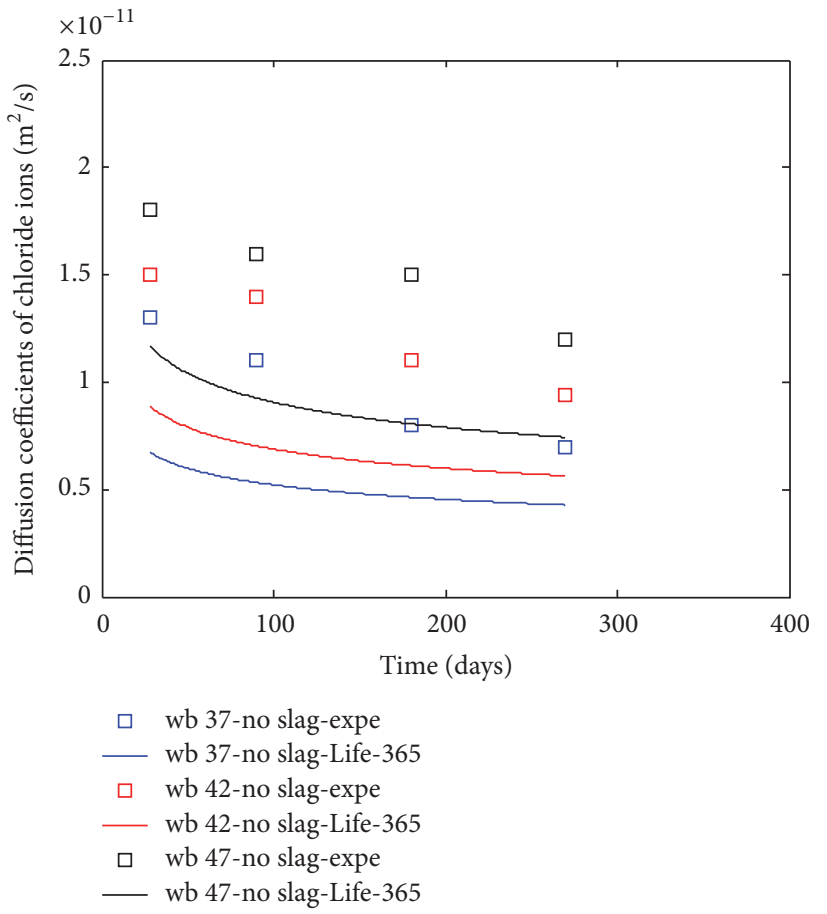

(a) Portland cement concrete

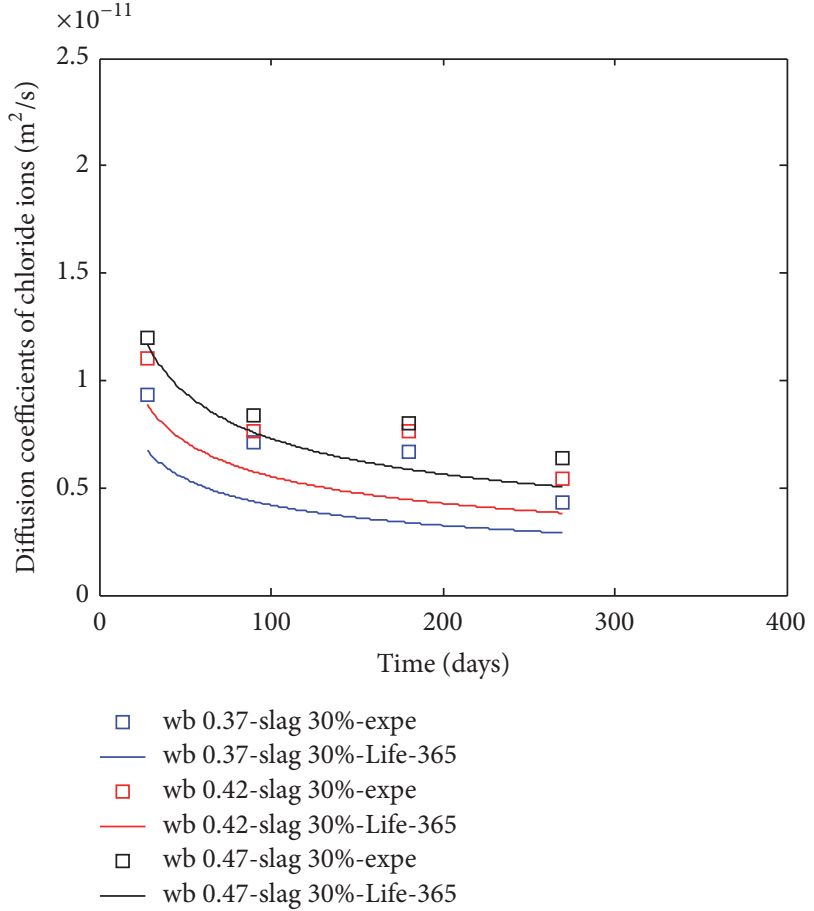

(b) $30 \%$ slag concrete

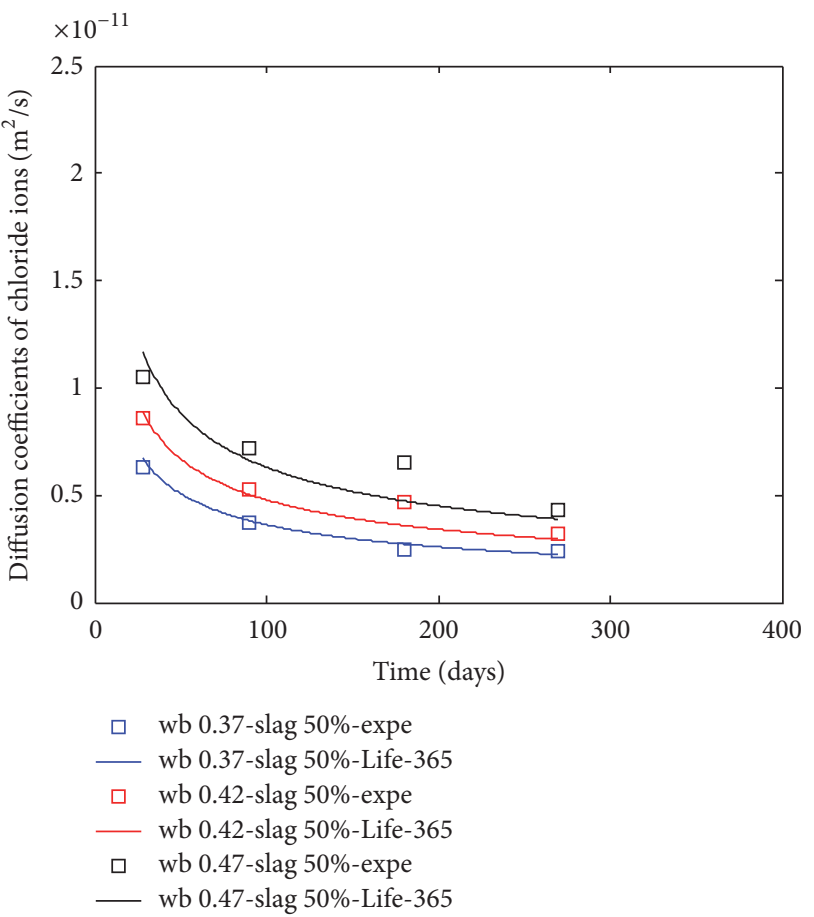

(c) $50 \%$ slag concrete

FIgURE 7: Chloride diffusion coefficients calculated from Life-365 model.

latent-hydraulic properties and pozzolanic reaction of slag are analyzed. The proposed model is valid for concrete with different water to binder ratios, slag replacement ratios, and curing ages.

\section{Competing Interests}

The authors declare that there is no conflict of interests regarding the publication of this paper. 


\section{Acknowledgments}

This research was supported by Basic Science Research Program through the National Research Foundation of Korea (NRF) funded by the Ministry of Science, ICT and Future Planning (no. 2015R1A5A1037548).

\section{References}

[1] K. Maekawa, T. Ishida, and T. Kishi, Multi-Scale Modeling of Structural Concrete, Taylor \& Francis, London, UK, 2009.

[2] V. G. Papadakis, "Effect of supplementary cementing materials on concrete resistance against carbonation and chloride ingress," Cement and Concrete Research, vol. 30, no. 2, pp. 291299, 2000.

[3] S. Demis, M. P. Efstathiou, and V. G. Papadakis, "Computeraided modeling of concrete service life," Cement and Concrete Composites, vol. 47, pp. 9-18, 2014.

[4] M. Alexander and M. Thomas, "Service life prediction and performance testing - current developments and practical applications," Cement and Concrete Research, vol. 78, pp. 155-164, 2015.

[5] http://www.life-365.org/.

[6] X.-Y. Wang and H.-S. Lee, "Modeling the hydration of concrete incorporating fly ash or slag," Cement and Concrete Research, vol. 40, no. 7, pp. 984-996, 2010.

[7] S.-H. Han, "Influence of diffusion coefficient on chloride ion penetration of concrete structure," Construction and Building Materials, vol. 21, no. 2, pp. 370-378, 2007.

[8] W.-J. Fan and X.-Y. Wang, "Prediction of chloride penetration into hardening concrete," Advances in Materials Science and Engineering, vol. 2015, Article ID 616980, 8 pages, 2015.

[9] H.-W. Song, J.-C. Jang, V. Saraswathy, and K.-J. Byun, "An estimation of the diffusivity of silica fume concrete," Building and Environment, vol. 42, no. 3, pp. 1358-1367, 2007.

[10] H.-W. Song, S.-W. Pack, S.-H. Nam, J.-C. Jang, and V. Saraswathy, "Estimation of the permeability of silica fume cement concrete," Construction and Building Materials, vol. 24, no. 3, pp. 315-321, 2010.

[11] B. H. Oh and S. Y. Jang, "Prediction of diffusivity of concrete based on simple analytic equations," Cement and Concrete Research, vol. 34, no. 3, pp. 463-480, 2004.

[12] M. Nokken, A. Boddy, R. D. Hooton, and M. D. A. Thomas, "Time dependent diffusion in concrete-three laboratory studies," Cement and Concrete Research, vol. 36, no. 1, pp. 200-207, 2006.

[13] Z. Yu and G. Ye, "New perspective of service life prediction of fly ash concrete," Construction and Building Materials, vol. 48, pp. 764-771, 2013.

[14] T. Luping and J. Gulikers, "On the mathematics of timedependent apparent chloride diffusion coefficient in concrete," Cement and Concrete Research, vol. 37, no. 4, pp. 589-595, 2007.

[15] H.-W. Song and S.-J. Kwon, "Evaluation of chloride penetration in high performance concrete using neural network algorithm and micro pore structure," Cement and Concrete Research, vol. 39, no. 9, pp. 814-824, 2009.

[16] B. H. Oh and S. Y. Jang, "Effects of material and environmental parameters on chloride penetration profiles in concrete structures," Cement and Concrete Research, vol. 37, no. 1, pp. 47-53, 2007.

[17] W. Chalee and C. Jaturapitakkul, "Effects of W/B ratios and fly ash finenesses on chloride diffusion coefficient of concrete in marine environment," Materials and Structures, vol. 42, no. 4, pp. 505-514, 2009.

[18] X.-Y. Wang, "Properties prediction of ultra high performance concrete using blended cement hydration model," Construction and Building Materials, vol. 64, pp. 1-10, 2014.

[19] E. J. Garboczi, "Microstructure and transport properties of concrete," in RILEM Report 12 Performance Criteria of Concrete Durability, J. Kropp and H. K. Hilsdorf, Eds., pp. 198-212, E\&FN Spon, London, UK, 1995.

[20] A. Princigallo, K. Van Breugel, and G. Levita, "Influence of the aggregate on the electrical conductivity of Portland cement concretes," Cement and Concrete Research, vol. 33, no. 11, pp. 1755-1763, 2003.

[21] J. C. Nadeau, "Water-cement ratio gradients in mortars and corresponding effective elastic properties," Cement and Concrete Research, vol. 32, no. 3, pp. 481-490, 2002.

[22] J. C. Nadeau, "A multiscale model for effective moduli of concrete incorporating ITZ water-cement ratio gradients, aggregate size distributions, and entrapped voids," Cement and Concrete Research, vol. 33, no. 1, pp. 103-113, 2003.

[23] D. N. Winslow, M. D. Cohen, D. P. Bentz, K. A. Snyder, and E. J. Garboczi, "Percolation and pore structure in mortars and concrete," Cement and Concrete Research, vol. 24, no. 1, pp. 2537, 1994.

[24] D. P. Bentz and E. J. Garboczi, "Simulation studies of the effects of mineral admixtures on the cement paste-aggregate interfacial zone," ACI Materials Journal, vol. 88, no. 5, pp. 518-529, 1991.

[25] Y. Gao, G. De Schutter, G. Ye, Z. Tan, and K. Wu, "The ITZ microstructure, thickness and porosity in blended cementitious composite: effects of curing age, water to binder ratio and aggregate content," Composites Part B: Engineering, vol. 60, pp. 1-13, 2014.

[26] Y. Gao, G. De Schutter, G. Ye, H. L. Huang, Z. J. Tan, and K. $\mathrm{Wu}$, "Characterization of ITZ in ternary blended cementitious composites: experiment and simulation," Construction and Building Materials, vol. 41, pp. 742-750, 2013.

[27] K. van Breugel, E. Koenders, Y. Guang, and P. Lura, "Modelling of transport phenomena at cement matrix-aggregate interfaces," Interface Science, vol. 12, no. 4, pp. 423-431, 2004. 

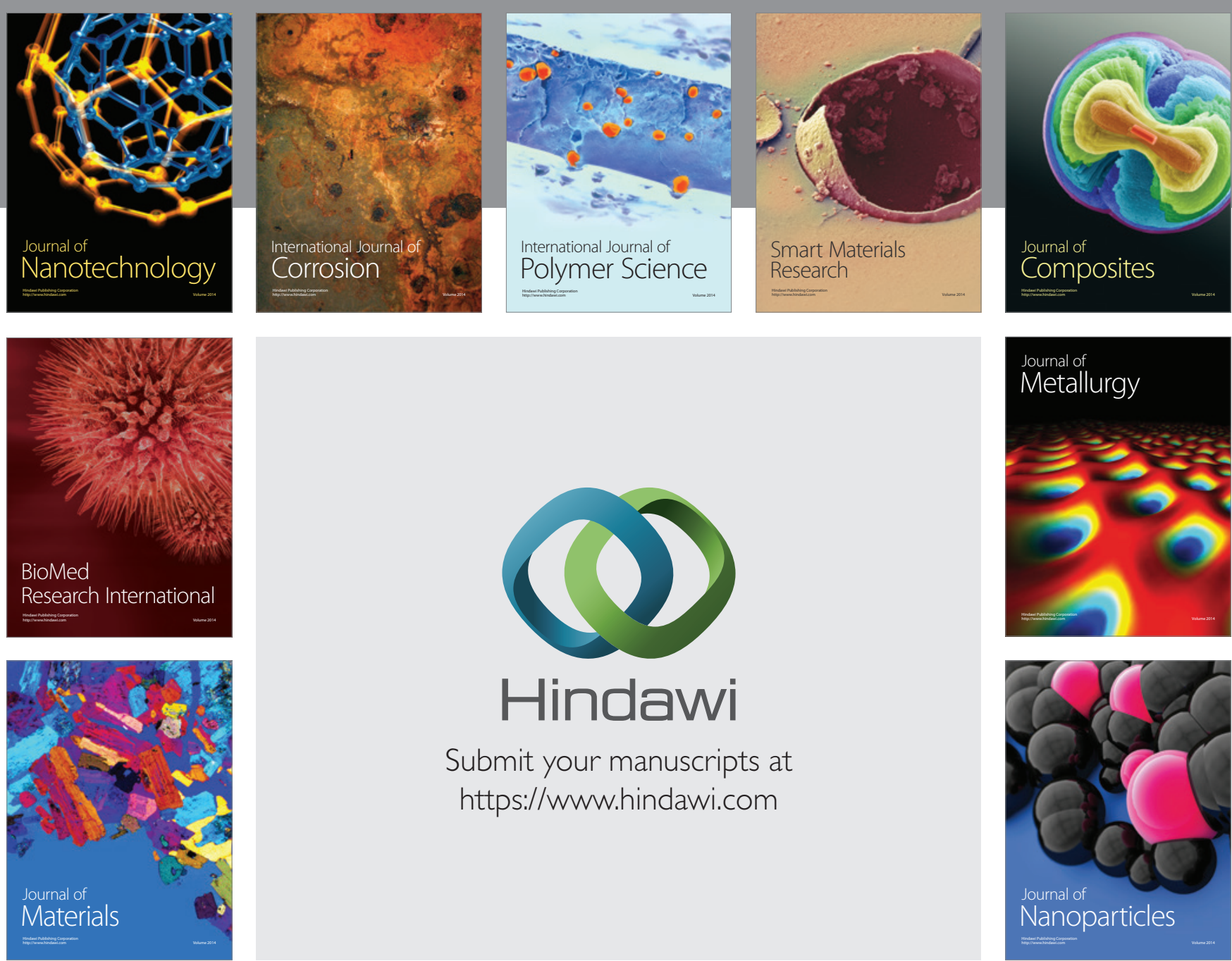

\section{Hindawi}

Submit your manuscripts at

https://www.hindawi.com

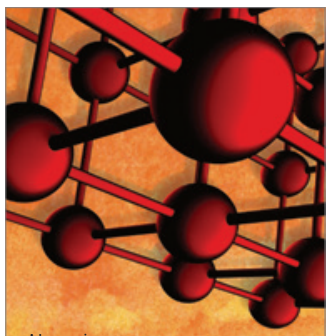

Materials Science and Engineering
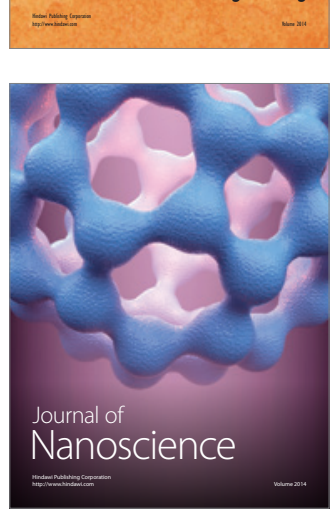
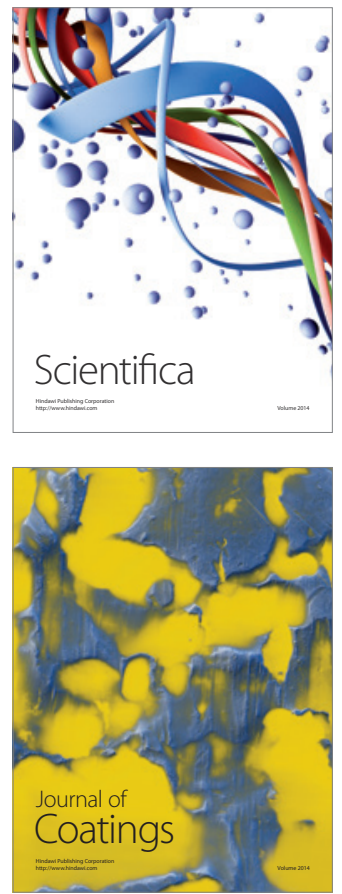
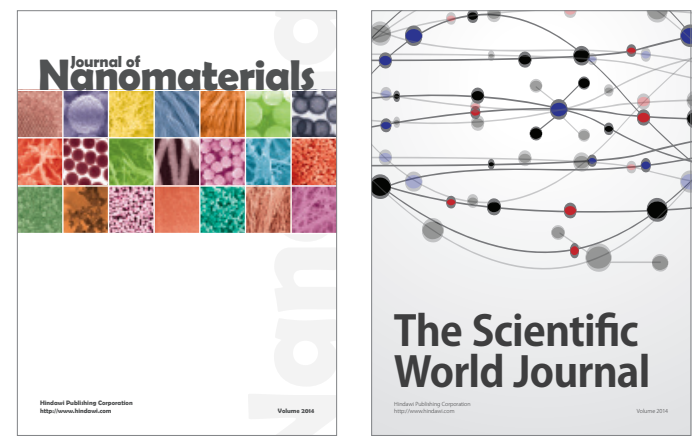

The Scientific World Journal
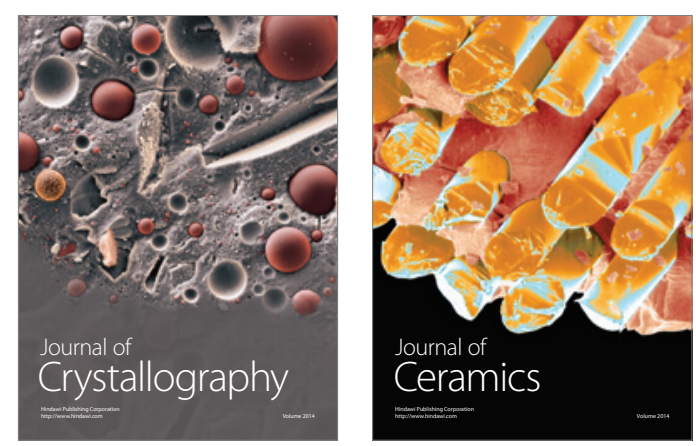
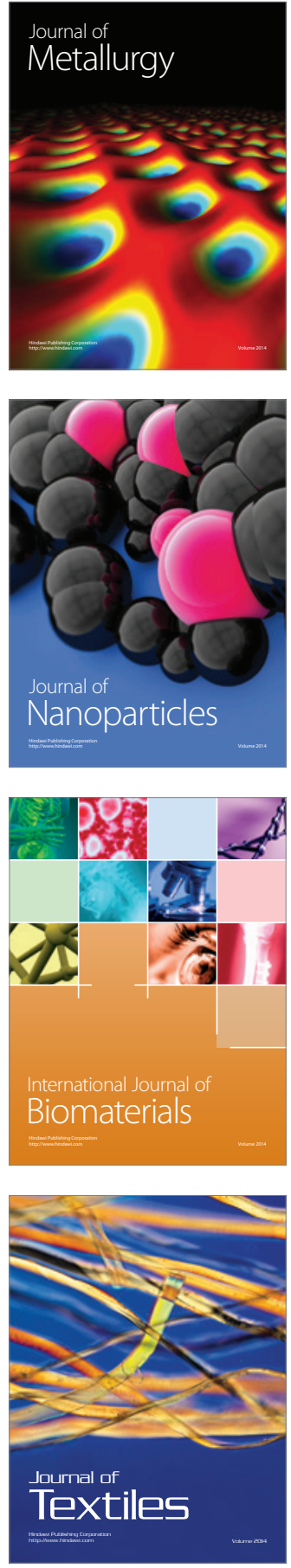